Res Publica. Revista de Historia de las Ideas Políticas ISSN: $1576-4184$

http://dx.doi.org/10.5209/RPUB.56470

\title{
Acerca de la relación entre derechos y deberes en la filosofía práctica kantiana. De la reciprocidad jurídica a la reciprocidad ética
}

\author{
Ileana Paola Beade*
}

Recibido: 22 de julio de 2016 / Aceptado: 10 de mayo de 2017

Resumen. En este trabajo abordamos el problema de la relación entre derechos y deberes en el marco de la filosofía práctica kantiana. A través de un análisis del concepto de derecho desarrollado en los Principios metafisicos del derecho, y del concepto de dignidad humana invocado en la segunda formulación del imperativo categórico, intentaremos mostrar que tanto el derecho natural como el deber de respetar la humanidad entendida como un fin en sí mismo, se fundan en la idea de un valor intrínseco del ser humano, fundado en la naturaleza racional y libre de la persona.

Palabras clave: Derecho; deber; dignidad; humanidad.

[en] On the relationship between rights and duties in Kant's practical philosophy. From juridical reciprocity to ethical reciprocity

\begin{abstract}
This paper considers the problem involved in the relationship between rights and duties in the frame of Kant's practical philosophy. Trough the analysis of the concept of right -as formulated in the Metaphysical first principles of the doctrine of right-and the concept of human dignity, addressed in the second formulation of the categorical imperative, I will try to show that both natural human rights and our duty to respect humanity as an end in itself rest on the idea of an intrinsic value of humanity, which in turn rests on the rational nature of human beings.
\end{abstract}

Keywords: Right; duty; dignity; humanity.

Sumario: 1. Introducción. 2. Derecho y obligación como conceptos correlativos. 3. El concepto de dignidad humana como fundamento de la obligación moral. 4. Algunas consideraciones finales

Cómo citar: Paola Beade, I. (2017). Acerca de la relación entre derechos y deberes en la filosofía práctica kantiana. De la reciprocidad jurídica a la reciprocidad ética, en Res publica 20.2, 275-291.

\section{Introducción}

En el marco de la doctrina jurídica kantiana, el concepto de derecho se halla indisolublemente vinculado con el concepto de ley. En efecto, un derecho no es derecho en sentido estricto sino en tanto se halla garantizado por leyes universales, i.e. leyes

Universidad Nacional de Rosario, Argentina

ileanabeade@yahoo.com.ar 
válidas para todos los individuos sin excepción ${ }^{1}$. Ambos conceptos -derecho y leyse hallan, a su vez, ligados al concepto de coacción [Zwang]: todo derecho supone una obligación correlativa, pues que un individuo posea un derecho significa, precisamente, que puede exigir a otros que respeten ese derecho, so pena de coacción ${ }^{2}$. Kant sostiene que el uso de la coacción es legítimo - es decir, concordante con la libertad de cada uno- sólo en tanto y en cuanto la coacción sea ejercida contra aquel que pone obstáculos a la libertad de otro. La coacción -entendida como la acción de coercionar a quien coerciona la libertad de otros individuos-resulta así conforme al derecho [recht], y todo derecho se halla ligado, por consiguiente, a "la facultad de coaccionar a quien lo viola, según el principio de contradicción”’”.

Kant define el derecho [das Recht] como "el conjunto de condiciones bajo las cuales el arbitrio de uno puede conciliarse con el arbitrio del otro según una ley universal de la libertad". A continuación establece el principio universal del derecho:

Una acción es conforme a derecho cuando permite, o cuya máxima permite, a la libertad del arbitrio de cada uno coexistir con la libertad de todos según una ley universal [...] El concepto de derecho, en tanto que se refiere a una obligación que le corresponde (es decir, el concepto moral del mismo), afecta, en primer lugar, solo a la relación externa y ciertamente práctica de una persona con otra, en tanto que sus acciones, como hechos, puedan influirse entre sí (inmediata o mediatamente) ${ }^{4}$.

Bajo el concepto general de derecho se incluyen tanto el derecho natural como el derecho positivo: el primero, fundado en principios a priori; el segundo, basado en la voluntad de un legislador. Asumiendo un principio básico de la tradición iusnaturalista, Kant sostiene que el legislador debe tomar del derecho natural "los principios inmutables para toda legislación positiva"s. Todo derecho individual, ya se trate de un derecho natural o de un derecho jurídico ${ }^{6}$, supone un deber para

1 Cf. I. Kant, La metafisica de las costumbres [Die Metaphysik der Sitten, 1797], traducción española de A. Cortina Orts y J. Conill Sancho, Madrid, Tecnos, 1994, Ak. VI, 232. La paginación citada corresponde a la edición académica de las obras kantianas: Kants gesammelte Schriften (vol. I-IX), Berlin, Herasugegeben von der Königlich Preussischen Akademie der Wissenschaften, 1902ss. A esta edición se alude bajo la abreviatura Ak., seguida del número de tomo, indicado en números romanos.

2 Ibidem, Ak. VI, p. 230.

3 Ibidem, Ak. VI, p. 231. Con el propósito de señalar la íntima conexión entre derecho y coacción, Kant indica que "derecho y facultad de coaccionar significan [...] una y la misma cosa" (Ibidem, Ak. VI, p. 232). Guyer observa, a propósito de esta afirmación, que ella no implica una relación de identidad lógica entre libertad y coacción: Kant sugiere allí que coaccionar a quien obstaculiza la libertad de otros hace posible la libertad de todos, y en tal sentido la coacción es considerada como una condición para el ejercicio de la libertad, derecho originario del ser humano (cf. P. Guyer, "Kant's Deductions of the Principles of Rights", en M. Timmons (ed.), Kant's Metaphisics of Morals Interpretative Essays, New York, Oxford University Press, 2004, pp. 23-63, aquí p. 51). Kersting señala, por su parte, que la equiparación entre derecho y coacción hace alusión a la garantía que ha de ser provista por el sistema legal en tanto sistema necesariamente avalado por un poder coactivo: la posibilidad de una coerción recíproca legal es aquello que permite garantizar el ejercicio de los derechos humanos originarios (cf. W. Kersting, "Politics, freedom, and order: Kant's political philosophy", en P. Guyer (ed.), The Cambridge Companion to Kant, Cambridge, Cambridge University Press, 1992, pp. 342-366, aquí p. 346).

4 Cf. Ibidem, Ak. VI, 230.

5 Ibidem, Ak. VI, 229.

6 Mulholland señala que la caracterización del derecho natural como derecho fundado en principios racionales constituye un rasgo claramente iusnaturalista en la filosofía jurídica kantiana: las leyes positivas son vinculantes 
otros. La existencia de derechos naturales u originarios -inherentes a todo hombre por su sola condición de tal- da lugar a obligaciones, que no constituyen obligaciones jurídicas hasta tanto no sea establecido un estado civil; en efecto, en el estado de naturaleza, el derecho natural sólo puede implicar para otros el deber moral de respetarlo, mas no una obligación jurídica, pues esta última presupone la existencia de leyes positivas, y de un poder político que garantice la eficacia de las mismas $^{7}$. La premisa iusnaturalista que establece la existencia de derechos inherentes al ser humano por su mera condición de tal, presupone, pues, de manera tácita, una obligación de carácter moral, a saber: la obligación de respetar el derecho del otro, reconociendo tal derecho como un atributo inalienable de su persona ${ }^{8}$, obligación que se funda -sostiene Kant- en principios racionales puros. Ahora bien, la doctrina jurídica kantiana establece un tránsito necesario del derecho natural al derecho positivo ${ }^{9}$, tránsito que tiene su correlato en el plano de la obligación: una vez instituida la sociedad civil, la obligación moral de respetar el derecho de otros pasará a constituir una obligación de carácter jurídico; con ello se opera un tránsito del derecho natural al derecho positivo.

En el marco de la teoría kantiana del contrato, se establece que, en virtud de un mandato incondicionado, los hombres ingresan en una comunidad jurídica, en cuyo marco el derecho natural se constituye como derecho en sentido estricto ${ }^{10}$. A partir de este acto contractual que da origen al orden civil, el deber moral (vinculante para los individuos en el estado de naturaleza) se desdobla -si cabe la expresión-, y da lugar a dos formas diversas de obligación: la obligación ética y la obligación jurídica; la primera concierne al ejercicio interno del arbitrio -esto es: a la libertad interna-, mientras que la segunda atañe al ejercicio externo del arbitrio o libertad externa.

Sobre la base de estas observaciones, podría concluirse que la obligación moral de un individuo para con otro surge a partir del reconocimiento del derecho que le es inherente en razón de su condición humana. Sin embargo, si atendemos a lo establecido por Kant en sus principales textos de filosofía moral, tal conclusión resulta problemática, ya que en diversos escritos sostiene Kant que el deber moral tiene origen en una ley objetiva originada en la razón práctica, ley cuyo carácter

no porque se funden en un consentimiento -o en el principio del contrato-, sino porque emanan de una ley natural entendida, en este marco, como ley racional (cf. L. Mulholland, Kant's System of Rights, New York, Columbia University Press, 1990, pp. 12-14).

7 La moral, en la acepción más amplia del término, incluye, para Kant, tanto a la ética como al derecho. Entendido como correlato del derecho natural, el deber moral es moral en un sentido amplio, es decir, no se trata de un deber específicamente ético, ni tampoco de un deber jurídico; en efecto, el derecho natural que se reconoce a todo hombre en su condición de tal, impone a otros un deber, que si bien concierne al ejercicio externo del arbitrio (esto es, a la libertad externa), no admite ser considerado como una obligación jurídica, pues el derecho natural rige en el estado de naturaleza, y hasta tanto no sea instituido el orden civil -i.e. hasta tanto el derecho natural no dé lugar al derecho positivo- no hay obligación jurídica alguna que coercione a los individuos a respetar el derecho de otros.

8 Al concepto de persona y su significado específico en el marco de la doctrina kantiana del derecho, haremos mayor referencia en el siguiente apartado.

$9 \quad$ En el marco de la teoría kantiana del contrato, se establece que los derechos naturales deben ser garantizados a través de la institución de leyes públicas; el derecho natural conduce necesariamente al derecho positivo, y esta necesidad es de carácter práctico, ya que el contrato es resultado de un mandato incondicionado de la razón pura práctica (cf. I. Kant, Teoría y práctica [Über den Gemeinspruch: Das mag in der Theorie richtig sein taugt aber nicht für die Praxis, 1793], Ak. VIII, 289).

10 Cf. I. Kant, La metafisica de las costumbres, Ak. VI, p. 232. 
incondicionado y absolutamente vinculante resulta expresado a través de la noción de imperativo categórico. La presencia de la ley moral en nosotros -y no el reconocimiento de derechos humanos originarios e inalienables- sería, pues, el origen de toda obligación moral. En este trabajo intentaremos indagar acerca de una posible concepción del deber como aspecto correlativo del derecho, a través de un análisis de la segunda formulación del imperativo categórico, aquella que prescribe obrar de tal modo que se use a la humanidad [Menschheit], tanto en la propia persona como en la persona de cualquier otro, siempre a la vez como fin y nunca simplemente como medio $^{11}$. Sugeriremos que el deber de respetar la humanidad en la persona del otro se funda en el reconocimiento de derechos inalienables del ser humano: a partir de la noción de un derecho humano natural se originan obligaciones morales, que a su vez darán lugar a obligaciones jurídicas, una vez instituido el estado civil. A fin de ilustrar este vínculo entre el derecho natural, la obligación moral, y la obligación jurídica, examinaremos, en primer lugar, el concepto de derecho, tal como aparece formulado en la primera parte de La metafisica de las costumbres. En segundo lugar, haremos referencia a la noción de dignidad [Würde] inherente a la persona humana, desarrollada en la segunda formulación del imperativo categórico (Fundamentación de la metafisica de las costumbres). A través de este análisis, intentaremos señalar aspectos que puedan ser relevantes para el esclarecimiento de la correlación entre derechos y deberes establecida en el marco de la filosofía práctica kantiana.

Cabe señalar, de manera preliminar, que el análisis que a continuación proponemos no pretende identificar a Kant como un antecedente directo del debate contemporáneo acerca de los derechos humanos; no obstante, y dado que se ha generado, durante las dos últimas décadas, una intensa discusión acerca de las afinidades y/o discrepancias entre el tratamiento kantiano de los derechos y el actual abordaje de los derechos humanos ${ }^{12}$, resulta conveniente aclarar, al menos esquemáticamente, nuestra posición al respecto. Si bien es indudable que conceptos implicados en tal debate -como el de justicia global, o el de derechos de las minorías- resultan ajenos a las cuestiones y problemas abordados en la teoría jurídica kantiana, es posible reconocer en Kant un antecedente relevante para la posterior reflexión en torno al problema de los derechos, fundamentalmente en lo que atañe a su tratamiento de la noción de dignidad humana, noción que, según entendemos, no puede estar ausente en una teoría de los derechos humanos. Más allá de que los contenidos específicos vinculados a la noción general de "derechos humanos" se hallan visto significativamente modificados en el transcurso del último siglo, permanece invariable cierta concepción del ser humano como sujeto de derecho: la sola pertenencia a la especie humana, la mera condición de ser humano, implica que se reconoce a todo individuo

11 Cf. I. Kant, Fundamentación de la metafísica de las costumbres, Ak. IV, 429.

12 Cf. K. Flickschuh, "Human Rights in Kantian Mode: A Sketch", en R. Cruft, S. Matthew Lliao, M. Renzo (eds.), Philosophical Foundations of Human Rights, Oxford University Press, Oxford, 2015, pp. 653-670; A. Sangiovanni, "Why there cannot be a truli Kantian Theory of Human Rights", en R. Cruft, S. Matthew Lliao, M. Renzo (eds.), Philosophical Foundations of Human Rights, Oxford University Press, Oxford, 2015, pp. 671-689; N. Sánchez Madrid, "Puede haber una fundamentación kantiana de los derechos humanos", en Revista de Estudios Kantianos, vol. 1, nº 2, 2016, pp. 191-206; N. Sánchez Madrid, "El carácter jurídico del cosmopolitismo kantiano: las condiciones de la extensión del derecho a escala global”, en J. M. Navarro cordón, R. Orden, R. Rovira (eds.): Kant en nuestro tiempo. Las realidades en que habitamos, Biblioteca Nueva, Madrid, 2016, pp. 207-220; A. Pinheiro Walla, "Common Possesion of the Earth and Cosmopolitan Right", Kant-Studien, vol. 107, 2016, pp. 160-178. 
la facultad de arrogarse derechos específicos, que serán determinados a partir de diversos contextos culturales.

Kant no se halla particularmente interesado en mostrar qué derechos específicos se derivan de nuestro derecho originario a la libertad: su objetivo, en la Doctrina pura del derecho, es establecer los principios puros (racionales) sobre los cuales ha de asentarse todo ordenamiento jurídico en general. Este objetivo delimita el ámbito específico de la investigación que lleva a cabo en La metafisica de las costumbres, y establece el núcleo conceptual básico sobre el que discurre la reflexión kantiana en torno al problema de los derechos. Cualquier indagación ulterior acerca de qué derechos pueden ser derivados a partir de los principios racionales fundamentales sobre los que se construye la teoría jurídica kantiana (como doctrina pura del derecho), constituye, indudablemente, un asunto de interés, pero se trata, sin embargo, de un asunto que trasciende el problema teórico específico al que Kant pretende dar solución en esa obra, abocada a la determinación de conceptos jurídicos elementales que puedan ser derivados a partir de la mera razón, sin intervención alguna de consideraciones empíricas (de carácter cultural o histórico). Una doctrina pura del derecho debe establecer los principios puros del orden jurídico en general, y en tal sentido proporciona un marco teórico ineludible para la posterior determinación o formulación de derechos jurídicos específicos, determinación que aparece, indudablemente, como una cuestión decisiva en el contexto de la actual reflexión acerca de los derechos humanos.

Por tal motivo, consideramos que es posible reconocer en Kant a una de las figuras de la modernidad que mayor impacto ha tenido en el desarrollo de la reflexión jurídico-política posterior. Se trata de un autor que ofrece herramientas conceptuales de indudable valor relevantes para todo desarrollo del concepto de derecho, herramientas entre las cuales se incluye un peculiar modo de entender la conexión entre la obligación ética y la obligación jurídica ${ }^{13}$. Si bien Kant establece una clara distinción entre ética y derecho en las secciones preliminares de La metafísica de las costumbres, es indudable que ambos dominios se articulan en el horizonte más amplio de la moralidad: ética y derecho constituyen expresiones o manifestaciones de la moral entendida en sentido amplio, y eso es, precisamente, lo que justifica la inclusión de una teoría del derecho y de una teoría de la virtud en La metafisica de las costumbres, obra en la que hayamos el desarrollo más sistemático de la filosofía jurídica kantiana. Esta vinculación indisoluble entre la noción de derecho, los principios morales (tales como el de imperativo categórico) y cierta concepción ético-antropológica del ser humano como sujeto racional (sujeto que se arroga derechos y que posee, por otra parte, obligaciones, tanto éticas como jurídicas) constituye el horizonte conceptual general en cuyo marco serán desarrolladas muchas de las actuales teorías de los derechos humanos.

A partir de este reconocimiento de Kant como un antecedente insoslayable en la reflexión filosófica acerca del derecho, podrán luego señalarse límites sin duda presentes en el tratamiento kantiano de la cuestión de los derechos humanos: podrá cuestionarse, por ejemplo, la ausencia de una preocupación por las condiciones materiales que posibilitan el ejercicio efectivo de los derechos, o cierta insuficiencia en el análisis kantiano de la relación entre derecho político y derecho cosmopolita; podrá objetarse asimismo el aparente desinterés de Kant por el problema de la justicia

Para un estudio de esta cuestión, remitimos a nuestro trabajo: I. Beade, "Ética y derecho en La metafisica de las costumbres", Ideas y valores, vol. 65, n 162, 2016, pp. 135-161. 
en lo que atañe a la cuestión de la equidad social. Es evidente que, en diversos aspectos, la teoría kantiana del derecho resulta insuficiente para abordar problemáticas de nuestra escena contemporánea, atravesada por conflictos que trascienden el horizonte teórico de la Ilustración, y que en buena parte no podían ser anticipados por los pensadores ilustrados. Sin embargo -insistimos-, reconocer estas limitaciones del tratamiento kantiano de los derechos no implica negar la importancia fundamental de dicho tratamiento para el desarrollo de la reflexión filosófica posterior. Si Kant ha sido -y continúa siendo - un interlocutor obligado para la teoría del conocimiento, la epistemología, la filosofía moral y la teoría política contemporáneas, su filosofía jurídica no constituye una excepción: también en este ámbito las nociones kantianas son aún un referente ineludible, ya sea que se las discuta, ya sea que se las recupere, total o parcialmente. Es por ello que consideramos erróneo negar toda relevancia de la teoría kantiana del derecho para el debate actual en torno al problema de los derechos humanos ${ }^{14}$.

En los apartados siguientes intentaremos examinar en detalle la relación que Kant establece, en su filosofía práctica, entre derecho y obligación, con el propósito de sugerir que en el concepto de dignidad humana se fundamenta toda obligación en general, ya se trate de la obligación moral o bien de la obligación jurídica. La noción de dignidad humana, desarrollada en el marco de la segunda formulación del imperativo categórico - esto es: la idea de un valor inherente a todo ser humano en virtud de su condición racional y de su voluntad libre- da lugar al reconocimiento de derechos humanos originarios. El ser humano posee dignidad, esto es: posee un valor intrínseco, que ningún individuo, ninguna acción, pueden vulnerar. Esta es la noción fundamental a partir de la cual ha de instituirse todo derecho positivo: la noción del individuo como sujeto racional y libre, cualidades que lo califican como sujeto de derecho. Observaremos que tanto los derechos (que el individuo puede arrogarse por su sola condición de ser humano), como los deberes para con otros (a los que se haya recíprocamente obligado), se derivan del status privilegiado de la persona en cuanto dotada de una racionalidad práctica. En este sentido, puede afirmarse que la teoría kantiana del derecho se funda en una concepción ético-antropológica que provee el repertorio conceptual básico en el cual abrevará la posterior reflexión filosófica acerca de los derechos humanos. Si bien aspectos puntuales de la teoría kantiana del Derecho penal -tales como la ley del talión, que establece que el castigo de un crimen debe ser proporcional en cantidad y cualidad a la naturaleza del acto delictivo, a partir de lo cual puede avalarse, por ejemplo, la humillación pública de quien delinque, e incluso la pena de muerte ${ }^{15}$ - deben ser rechazados bajo las premisas de los actuales defensores de los derechos humanos, ello no implica negar la importancia del tratamiento kantiano del concepto de derecho como concepto esencialmente vinculado a la noción de una dignidad intrínseca e inviolable de la persona.

14 Cabe señalar, por otra parte, que el análisis que proponemos acerca de la conexión entre derechos y deberes en la filosofía kantiana, no pretende de ningún modo aportar elementos en favor de una interpretación liberal de la filosofía político-jurídica kantiana. Entendemos que el debate acerca de la filiación de Kant con el liberalismo, o bien con el republicanismo, exige abordar una serie de aspectos que van más allá de su concepción de la relación entre ética y derecho. A esta cuestión nos hemos referido en trabajos previos: I. Beade, "Consideraciones acerca de la concepción kantiana de la libertad en sentido político", en Revista de Filosofía (Universidad de Chile), vol. 65, 2009, pp. 25-42; I. Beade, "Liberalismo y republicanismo en la concepción kantiana de «ciudadanía»", en Reflexión Politica (Colombia), vol. 9, nº 17, 2007, pp. 58-74.

15 Cf. I. Kant, La metafisica de las costumbres, Ak. VI, 331ss. 


\section{Derecho y obligación como conceptos correlativos}

En la Introducción a La metafisica de las costumbres, los principios prácticos que determinan la voluntad humana son caracterizados como leyes de la libertad, leyes irreductibles a la ley natural. Tales leyes se denominan asimismo leyes morales, y abarcan tanto las leyes jurídicas como las éticas (las primeras afectan únicamente a las acciones externas, mientras que las segundas afectan asimismo al ejercicio interno del arbitrio $)^{16}$. Kant define a la legislación ética como aquella que hace de la acción un deber y de este deber, un móvil, por oposición a la legislación jurídica, que admite un móvil distinto del deber, a saber: la aversión a la coacción (que es, en general, aquello que nos compele a obedecer las normas jurídicas) ${ }^{17}$. Si bien en este escrito se caracteriza a la moral como un ámbito amplio, en cuyo marco se inscriben tanto la ética como el derecho, los principios jurídicos no pueden ser entendidos como una mera derivación, aplicación o especificación de principios éticos generales, ya que cuentan con una especificidad propia, que está dada, según señalamos, por el carácter externo de la obligación jurídica ${ }^{18}$. Esta externalidad propia del derecho (entendido como un conjunto de condiciones que regulan el ejercicio externo de una multiplicidad de arbitrios libres) denota su dimensión esencialmente intersubjetiva $^{19}$. En efecto, mientras que a la ética le concierne la independencia del arbitrio individual con respecto a las leyes naturales e inclinaciones sensibles que nos condicionan en tanto seres empíricos, al derecho le atañe la independencia del arbitrio individual respecto del arbitrio constrictivo de otros individuos. Ética y derecho remiten, pues, a la independencia propia del arbitrio humano, pero considerada ésta en dos sentidos diversos -i.e. la independencia respecto de las inclinaciones sensibles y la independencia respecto de otros- y el ámbito de incumbencia de cada uno de estos dominios se define, por consiguiente, en relación con modos diversos de incompatibilidad: la incompatibilidad intrasubjetiva -aquella que puede darse entre la máxima y el mandato objetivo de la ley moral- y la incompatibilidad intersubjetiva, que puede tener lugar entre diversos arbitrios, cada uno de los cuales persigue sus propios fines y propósitos ${ }^{20}$.

Una vez establecido el ámbito de incumbencia propio del derecho, podemos atender a la clasificación de diversos tipos de derechos, formulada en la Introducción a la doctrina del derecho. Kant declara allí que la libertad es el único derecho innato del hombre, apoyándose en una clasificación previa de los derechos en la que atiende a dos criterios diversos. Si se consideran los derechos como preceptos [Lehren], cabe distinguir entre el derecho natural (fundado en principios a priori) y el derecho po-

\footnotetext{
Ibidem, Ak. VI, 214.

Ibidem, Ak. VI, 219.

18 Cf. A. Wood, “The Final Form of Kant's Practical Philospohy”, en M. Timmons (ed.), Kant's Metaphysics of Morals Interpretative Essays, Oxford University Press, New York, 2004, pp. 1-22, aquí pp. 9ss. Para un estudio pormenorizado de la relación entre ética y derecho como dimensiones del ámbito moral, cf. I. Beade, "Ética y derecho en La metafísica de las costumbres", Ideas y valores, vol. 65, n 162, 2016, pp. 135-161.

19 Cf. A. Ripstein, Force and Freedom. Kant's Legal and Political Philosophy, Cambridge, Harvard University Press, 2009, p. 358. Un individuo que viviese absolutamente asilado de otros no tendría, en sentido estricto, derechos, ya que el derecho de uno supone simplemente una autorización para la restricción legal de las acciones de otros individuos (cf. S. Byrd \& J. Hruschka, Kant's Doctrine of Right. A Commentary, New York, Cambridge University Press, 2010, p. 79).

20 Cf. A. Ripstein, op. cit., pp. 366-371.
} 
sitivo (aquel que procede de la voluntad de un legislador). Si se consideran, en cambio, los derechos, no ya como preceptos sino como facultades [Vermögen], entonces puede establecerse una distinción entre derechos innatos y derechos adquiridos: los primeros corresponden a todo hombre por naturaleza, es decir, con independencia de todo acto jurídico, por oposición a los segundos, que sí requieren un acto de ese tipo. Invocando la noción de derecho innato introducida en esta segunda clasificación, Kant declara que "la libertad (la independencia con respecto al arbitrio constrictivo de otro), en la medida en que puede coexistir con la libertad de cualquier otro según una ley universal, es este derecho único, originario, que corresponde a todo hombre en virtud de su humanidad" 21 . Una primera observación respecto de esta caracterización de la libertad como único derecho innato [angeborne] u originario [ursprüngliche], es que se trata aquí de una concepción jurídico-política de la libertad. Si bien podría objetarse que tal definición no es aún estrictamente jurídica, por cuanto alude a la libertad, no como derecho adquirido, sino como derecho innato, consideramos que cabe considerarla como una definición jurídica en tanto se trata aquí de un derecho originario que ha de ser garantizado a través de la institución de un orden jurídico-político ${ }^{22}$. El derecho a la libertad que es inherente a todo hombre supone, para otros, la obligación de reconocer y respetar su independencia individual, y el cumplimiento de esta obligación debe ser garantizado bajo leyes públicas coactivas, ya que de otro modo la libertad no podría constituirse, propiamente, como un derecho ${ }^{23}$. En este sentido, podría afirmarse que el derecho innato del hombre a la libertad no es, en última instancia, sino un derecho a la independencia garantizada bajo leyes públicas. De este modo, el derecho natural del hombre a la libertad puede ser interpretado como un derecho originario a la libertad civil $^{24}$.

Una segunda observación respecto de esta definición de la libertad como derecho natural o innato es que en ella se invoca un concepto que Kant asocia de manera recurrente al concepto de libertad, esto es: el concepto de independencia ${ }^{25}$. También

21 I. Kant, La metafísica de las costumbres, Ak. VI, 237. Para un análisis pormenorizado del concepto de humanidad en conexión con la exhortación kantiana a respetar la humanidad en la propia persona y en la persona del otro, cf. V. Gerhardt: "Die Menschheit in der Person des Menschen. Zur Anthropologie der menschlichen Würde bei Kant", en H. Klemme (ed.), Kant und die Zukunft der europäischen Aufklärung, Walter de Gruyter, Berlin, 2009, pp. 269-291.

22 Cf. A. Ripstein, op. cit., p. 23.

23 Willaschek señala al respecto que todo lo que se enuncia en la noción kantiana de derecho es la autorización a coercionar a otros a un comportamiento acorde con el sistema jurídico (cf. M. Willaschek, "Which Imperatives for Right? On the Non-Precriptive Character of Juridical Laws in Kant's Metaphysics of Morals", en M. Timmons (ed.), Kant's Metaphysics of Morals Interpretative Essays, New York, Oxford University Press, 2004, pp. 65-88, aquí pp. 80-82).

24 Es la necesidad de garantizar el derecho originario del hombre a la libertad aquello que conduce a la instauración de un orden jurídico, en cuyo marco pueda ser ejercido plenamente ese derecho. Dado que sin sociedad civil -i.e. sin leyes públicas coactivas, amparadas por un poder político que garantice el cumplimiento de las mismas- no es posible garantizar el derecho en cuanto tal, es decir, no es posible hablar de derechos en sentido estricto, el derecho natural puede ser pensado como un proto-derecho (cf. A. Ripstein, op. cit., pp. 9 ss.).

25 Ripstein señala que "la independencia es el principio básico del derecho. Ella garantiza una libertad equitativa, y demanda que nadie se halle sujeto al arbitrio constrictivo de otros [...]. Los límites impuestos a la independencia individual generan una serie de restricciones que son por naturaleza igualmente vinculantes para todos [...]. Kant intenta mostrar que la independencia, entendida de este modo, supone un dominio de limitaciones recíprocas" (A. Risptein, op. cit., p. 26). La independencia, invocada en la definición de la libertad en sentido jurídico, es de carácter interpersonal, a diferencia del concepto de independencia al que se refiere Kant en sus escritos morales, esto es: la independencia del arbitrio con respecto a las determinaciones sensibles o inclinaciones 
en su definición de la igualdad -una de las facultades incluidas en el derecho innato a la libertad ${ }^{26}$ - recurre Kant al concepto de independencia: la igualdad innata es caracterizada, en efecto, como "la independencia que consiste en no ser obligado por otros sino a aquello a los que también recíprocamente podemos obligarles"27. Si la libertad y la igualdad de cada individuo suponen una obligación para otros, y el cumplimiento de esta obligación sólo puede ser garantizado bajo la sujeción de todos a leyes coactivas de carácter público, libertad e igualdad suponen una reciprocidad en la obligación. Esto significa que un individuo no puede obligar a otros a que reconozcan un derecho que le es propio, sino en la medida en que acepte reconocer a éstos ese mismo derecho. Ahora bien, esta reciprocidad en la obligación no puede darse en el estado de naturaleza, ya que en tal estado no hay ley positiva alguna que pueda garantizarla. Por tal razón sostiene Kant que a partir del derecho natural surge el derecho público: si la libertad constituye un derecho natural, el ejercicio efectivo de este derecho no es posible sino en el marco de un estado de derecho público, esto es, en el marco de una asociación civil ${ }^{28}$. La reivindicación kantiana de la libertad como un derecho innato del hombre se halla, así pues, indisolublemente ligada a la exigencia de instituir un estado de derecho público, entendido éste como el conjunto de condiciones bajo las cuales pueden ser garantizados los derechos humanos originarios, inherentes a todo hombre por su sola condición de tal. Y en tal sentido hemos sugerido que, en el marco de la doctrina jurídica kantiana, el derecho innato del hombre a la libertad no es sino un derecho a la independencia garantizada bajo leyes públicas y, por consiguiente, un derecho (originario) a la libertad civil.

El derecho puede ser definido, del modo más amplio posible, como una facultad propia del ser humano para hacer legal o legítimamente lo que atañe a los fines de su vida (la noción de legalidad y de legitimidad se hallan indisolublemente vinculadas, en efecto, con la noción de derecho). El hombre posee la facultad de realizar acciones muy diversas, pero sólo aquellas que puede realizar de manera legítima-i.e. de manera justa- son acciones que tiene derecho $a$ realizar. Este derecho a actuar de cierto modo, a realizar determinadas acciones, se origina en su propia su condición humana (eso es lo que implica, precisamente, la noción de derecho natural); sin embargo, su derecho natural debe ser protegido y garantizado a través de leyes públicas $\mathrm{y}$ de un poder que las respalde, y en este sentido puede denominarse derecho a la fa-

patológicas que lo condicionan. En el plano jurídico, el concepto de independencia asume un sentido eminentemente intersubjetivo (cf. A. Ripstein, op. cit., pp. 36-38). Sobre este punto, cf. asimismo: K. Flikschuh, Kant and Modern Political Philosphy, Cambridge, Cambridge University Press, 2004, p. 88.

26 Cf. I. Kant, La metafísica de las costumbres, Ak. VI, 238.

27 Ibidem, Ak. VI, 237.

28 El tránsito del derecho natural al derecho público es desarrollado por Kant en su tratamiento del derecho de propiedad, cuestión fundamental para el desarrollo de la doctrina jurídica kantiana. Dado que la posesión de objetos o bienes en el estado de naturaleza sólo puede ser provisional, es necesario ingresar en un estado civil a fin de que la posesión puede constituirse como propiedad legal en sentido estricto. Sólo bajo leyes públicas, un individuo puede obligar a otros a abstenerse de hacer uso de lo que es suyo, bajo la condición de que aquél acepte respetar, recíprocamente, la propiedad de otros (cf. I. Kant, La metafísica de las costumbres, Ak. VI, 307ss.). Para un análisis de la teoría kantiana de la propiedad y su función en la justificación del orden legal, cf. R. Pippin, "Mine and thine? The Kantian State", en P. Guyer (ed.), The Cambridge Companion to Kant and Modern Philosophy. Cambridge, Cambridge University Press, 2007, pp. 416-446; H. Williams, “Kant's concept of property", en Philosophical Quarterly 27, 1973, pp. 32-40; H. Fulda, "Erkenntnis der Art, etwas Äusseres als Seine zu haben”, en O. Höffe (ed.), Metaphysische Anfangsgründe der Rechtslehre, Berlin, Akademie Verlag, 1999, pp. 87-115. 
cultad de hacer o exigir todo aquello que la ley o la autoridad establecen en nuestro favor (aquello que las leyes permiten, o al menos no prohíben). En síntesis: si bien el derecho parece ser una consecuencia natural de la condición de persona, la efectividad del derecho requiere de instituciones sociales que posibiliten su garantía legal, y así el derecho pasa de ser una facultad -inherente al ser humano- para constituir un conjunto de normas (que expresan cierta idea de orden y de justicia), normas cuya observancia puede ser impuesta de manera coactiva.

Una vez dilucidadas algunas de las premisas fundamentales implicadas en la concepción kantiana del derecho, podemos preguntarnos porqué es posible concebir al hombre como un sujeto de derecho, qué es aquello que permite establecer la existencia de derechos humanos originarios ¿Qué es lo que dota al hombre de una dignidad especial, en virtud de la cual se concibe a sí mismo como un ser dotado de un conjunto de atributos o facultades usualmente conceptualizadas bajo el concepto de derecho? Kant sostiene que la libertad es un derecho innato del hombre, pero no ofrece argumentos que justifiquen esta afirmación, sino que parece simplemente asumir que el hombre posee derechos naturales inalienables. Afirma, por otra parte, que los hombres deben abandonar el estado de naturaleza e instituir un orden civil, i.e. un estado de derecho público, pero no intenta demostrar esta afirmación, sino que se limita a invocar un mandato práctico incondicionado, una exigencia de la razón pura práctica, en virtud de la cual somos compelidos a ingresar en una constitución civil, a fin de garantizar el pleno ejercicio de nuestros derechos naturales. El derecho parece ser así el punto de partida axiomático, la premisa no demostrada (e indemostrable) en el marco de sus reflexiones jurídicas ${ }^{29}$. En otras palabras: el derecho se asume existente, y a partir de él emanan -según hemos indicado- ciertas obligaciones, que pueden ser caracterizadas como obligaciones de carácter moral -hasta tanto no sea instituido el orden civil-, pero que dan lugar luego a deberes jurídicos. La obligación moral de respetar el derecho de otros no parece ser suficiente para obligarnos a evitar toda acción que atente contra ese derecho, y esta insuficiencia del deber moral (que obliga de manera incondicionada, pero no es obedecido de manera necesaria, en virtud de nuestra doble condición, sensible e inteligible) hace necesario el establecimiento de normas jurídicas ${ }^{30}$.

Ante la ausencia de argumentos que justifiquen la tesis que establece la existencia de derechos humanos naturales, ¿es posible fundar la noción de derecho en la idea de una dignidad humana, es decir, de un valor intrínseco, inherente al hombre por su sola condición de tal? Y si ese fuera el caso, ¿qué es aquello que permite reconocerlo como titular de derechos originarios que deben ser respetados y garantizados, más allá de toda condición? En la sección siguiente, examinaremos el modo en que

${ }^{29}$ Byrd y Hruschka señalan que "el supuesto de que todo individuo posee derecho a la libertad externa es el punto de partida de la doctrina kantiana del derecho. Este derecho es originario en el sentido de que cada uno posee un derecho tal en el estado de naturaleza o en virtud de una ley que es conocida a priori por la razón (ley natural)" (S. Byrd \& J. Hruschka, op. cit., pp. 78-79).

30 Williams observa, respecto de este punto, que dado que el hombre no actúa necesariamente de manera acorde con el mandato de la ley moral, ésta no resulta suficiente para regular la conducta externa, sino que para ello se requiere asimismo de leyes positivas. Es, así pues, la imperfección moral de la voluntad humana (i.e. la posibilidad de una conducta heterónoma) aquello que torna necesaria una legislación externa que garantice la coexistencia pacífica de múltiples arbitrios libres, y haga posible las condiciones mínimas exigidas para un ejercicio de los derechos originarios. En tal sentido -concluye Williams- la filosofía del derecho supone una extensión o ampliación de la filosofía moral (cf. H. Williams, Kant's Political Philosophy, Oxford, Basil Blackwell, 1983, pp. 60ss.). 
Kant concibe la noción de dignidad humana, a fin de intentar dar respuesta a estos interrogantes.

\section{El concepto de dignidad humana como fundamento de la obligación moral}

En la Fundamentación de la metafísica de las costumbres, Kant establece que el criterio para determinar el valor moral de una acción está dado por la posible universalización de la máxima ${ }^{31}$. Este criterio recibe su forma sistemática en la primera formulación del imperativo categórico: "obra sólo según aquella máxima por la cual puedas querer que al mismo tiempo se convierta en una ley universal" ${ }^{\prime 32}$. Una segunda formulación del imperativo -que es la que interesa considerar aquí- invoca la noción del hombre como fin en sí mismo: "Obra de tal modo que uses a la humanidad [Menschheit], tanto en tu persona como en la persona de cualquier otro, siempre al mismo tiempo como fin y nunca simplemente como medio"33. En el marco de una serie de consideraciones previas a esta segunda fórmula, Kant define la voluntad como la capacidad, inherente a todo ser racional, de auto-determinarse a obrar según la representación de principios o leyes ${ }^{34}$. La noción de voluntad no sólo se halla ligada al concepto de ley, sino que se la vincula, por otra parte, con el concepto de fin: los fines que una voluntad racional se propone como efectos de sus acciones son relativos, pues su relación con la voluntad es lo que les confiere algún valor. Fines meramente relativos no pueden ser fundamento de un imperativo categórico-i.e. de un mandato absolutamente incondicionado-, sino que sólo pueden dar lugar a imperativos hipotéticos. El carácter incondicionado del imperativo categórico sólo puede fundarse en algo cuya existencia posea un valor absoluto, esto es: el ser humano, quien, en su condición de ser racional, existe como fin en $\mathrm{Si}^{35}$. Con el propósito de aclarar esta caracterización del hombre como fin en sí, Kant establece una distinción entre personas y cosas: éstas no poseen un valor absoluto, sino sólo relativo, es decir, sirven como medios para la realización de algún fin, a diferencia de las personas, que son fines en sí, i.e. que jamás puede ser utilizada como meros medios ${ }^{36}$.

31 Cf. I. Kant, Fundamentación para una metafisica de las costumbres [Grundlegung zur Metaphysik der Sitten, 1795], traducción española de R. Rodríguez Aramayo, Madrid: Alianza, 2005, Ak. IV, 403.

32 Ibidem, Ak. IV, 420-421

33 Ibidem, Ak. IV, 429.

34 Ibidem, Ak. IV, 127. Para un análisis del concepto kantiano voluntad, cf. I. Beade, "Acerca de la relación entre los conceptos de libertad, voluntad y arbitrio en la filosofía trascendental kantiana”, en Kant e-prints 9, 2, 2014, pp. 58-76.

35 Cf. I. Kant, Fundamentación para una metafisica de las costumbres, Ak. IV, 429.

36 En el marco de la doctrina jurídica kantiana, el concepto de persona se halla indisolublemente ligado a las nociones de imputabilidad, libertad y autonomía: "Persona es el sujeto cuyas acciones son imputables. La personalidad moral, por tanto, no es sino la libertad de un ser racional sometido a leyes morales [...], de donde se sigue que una persona no está sometida a otras leyes más que las que se da a sí misma (bien sola o, al menos, junto con otras" (I. Kant, La metafísica de las costumbres, Ak. VI, 23). La persona se dicta leyes a sí misma en cuanto persona moral; en cuanto persona jurídica, se auto-legisla en la medida en que participa en la elección de representantes en quienes delega la función legislativa. La noción de persona, tanto en sentido moral como jurídico, hace referencia a un ser libre, autónomo, al que pueden serle imputadas las acciones que realiza. Una cosa no es susceptible de imputación alguna, pues carece de libertad, esto es, carece de una voluntad racional que le permita determinarse a actuar según ciertos principios. Persona es, en síntesis, aquel ser que puede arrogarse la independencia que consiste en no estar sujeto al arbitrio constrictivo de otros (cf. B. Ludwig, Bernd, "Whence Public Right? The Role of Theoretical and Practical Reasoning in Kant's Doctrine of Right", en M. 
Sobre la base de estas precisiones terminológicas, referidas a los conceptos de voluntad y de fin, Kant introduce la segunda formulación del imperativo categórico, usualmente caracterizada, por los intérpretes, como la fórmula de la humanidad. Pese a las frecuentes objeciones referidas al carácter individualista y formal de la doctrina ética kantiana, la segunda formulación del imperativo categórico introduce, en dicha doctrina, la cuestión de la intersubjetividad, estableciendo el valor incondicionado de la persona como fin en sí mismo, valor que establece una condición limitativa para toda acción humana. En efecto, a partir de esta segunda formulación se infiere directamente que ninguna acción puede vulnerar la dignidad propia del hombre, sin transgredir con ello el mandato de la ley moral ${ }^{37}$.

En La metafisica de las costumbres, Kant define el fin como el objeto de la voluntad de un ser racional, a través de cuya representación la voluntad se determina a actuar, en pos de la realización de dicho objeto o propósito ${ }^{38}$. Sin embargo, la humanidad no constituye un fin en el sentido de que puede ser realizada a través de una determinada acción, sino que es fin en tanto proporciona a la voluntad un fundamento objetivo para su autodeterminación ${ }^{39}$. En este sentido, es fin a aquello que nos provee de una razón o fundamento para actuar. El hombre, la humanidad, son fines en tanto estamos moralmente obligados a actuar de manera tal que nuestras acciones respeten la condición humana de otros y, más precisamente, su condición de seres racionales, aquella que los dota de un valor intrínseco ${ }^{40}$. Afirmar que la humanidad es un fin en sí supone, pues, que nuestros actos no deben comprometer o vulnerar el valor absoluto de la persona, y ello establece un criterio negativo que permite evaluar el valor moral de toda acción en general: podemos considerar moralmente buena aquella acción que no atente contra el valor intrínseco de la humanidad (tanto en mi propia persona como en la persona del otro).

Otra de las formulaciones del imperativo categórico $^{41}$ establece que el hombre debe actuar "sólo de tal modo que la voluntad pueda considerarse a sí misma por su máxima al mismo tiempo como universalmente legisladora" ${ }^{42}$. Como sujeto racional, el hombre se dicta la ley moral a sí mismo, es decir, se autolegisla, y en ello reside, precisamente, su dignidad: en el hecho de no hallarse sometido -en ámbito del ejercicio interno del arbitrio- a la voluntad constrictiva de otros, sino únicamente al mandato de la ley moral, originada en su razón ${ }^{43}$. La autonomía no sólo eleva

Timmons (ed.), Kant's Metaphysics of Morals Interpretative Essays, New York, Oxford University Press, 2004, pp. 159-184, aquí p. 165).

37 "Este principio de la humanidad y de cualquier ser racional en general como fin en sí mismo [...] supone la máxima condición restrictiva de la libertad de las acciones de cada hombre" (I. Kant, Fundamentación para una metafisica de las costumbres, Ak. IV, 429)

38 Ibidem, Ak. IV, 384-385.

39 Ibidem, Ak. IV, 427. La humanidad no es un fin que debe ser producido sino un fin que debe ser respetado (cf. S. Kerstein, Kant's Search for the Supreme Principle of Morality, Cambridge, Cambridge University Press, 2002, p. 177).

40 Paton señala que la noción de humanidad hace referencia a la voluntad racional, como capacidad en virtud de la cual no podemos ser tratados como meros medios, sino siempre, a la vez, como fines (cf. H. J. Paton, The Categorical Imperative, Londres, Hutchinson, 1967, p. 165). Kerstein observa que el término humanidad alude, en este contexto, a la capacidad racional de actuar bajo principios y de perseguir fines a través de nuestras acciones (cf. S. Kerstein, op. cit., p. 175).

41 Para un análisis de la relación entre las diversas formulaciones del imperativo categórico, cf. P. Stratton-Lake, "Formulating Categorical Imperatives", Kant-Studien 84, 1993, pp. 317-340.

42 I. Kant, Fundamentación de la metafísica de las costumbres, Ak. IV, 434.

43 En conexión con la llamada fórmula de la autonomía, Kant introduce la noción de un reino de los fines: "[U] 
nuestra dignidad por encima del valor de todo ser natural ${ }^{44}$, sino que es, además, "el fundamento de la dignidad humana y de toda naturaleza racional" 45 . Mientras que las cosas tienen precio - esto es, pueden ser intercambiadas por algo que ostente un valor equivalente-, los hombres poseen un valor intrínseco [einen innern Werth], es decir, poseen dignidad [Würde $]^{46}$, situándose así más allá de toda equivalencia posible ${ }^{47}$. Su valor reside, pues, en su condición moral, que es resultado, a su vez, de su condición racional: "la moralidad y la humanidad, en la medida en que ésta es susceptible de aquélla, es lo único que posee dignidad"48.

En la Doctrina de la virtud (segunda parte de La metafisica de las costumbres), Kant señala que toda acción humana persigue un fin, y entre los múltiples fines que persiguen los hombres al actuar, algunos son representados por la razón como deberes, esto es, como fines que tienen que ser buscados necesariamente ${ }^{49}$. Los fines que la razón se representa como deberes son, específicamente, la propia perfección y la felicidad ajena ${ }^{50}$. Estamos moralmente obligados a buscar la propia perfección, es decir, a desarrollar nuestras facultades o disposiciones naturales -entendimiento y voluntad-, a superar la ignorancia, a rectificar nuestros errores, a ampliar nuestros conocimientos y a perfeccionarnos en sentido moral, es decir, a cultivar nuestra capacidad de sujetarnos al mandato de la ley moral ${ }^{51}$. Tales deberes nos son impuestos por la razón pura práctica, y su fundamento reside en la dignidad propia de la humanidad: la búsqueda de la propia perfección es un fin que nos representamos como un deber, ya que debemos hacernos dignos de la humanidad que habita en nosotros ${ }^{52}$.

n ser racional pertenece al reino de los fines como miembro si legisla universalmente dentro del mismo, pero también está sometido él mismo a esas leyes. Pertenece a dicho reino como jefe cuando como legislador no está sometido a la voluntad de ningún otro" (Ibidem, Ak. IV, 433). El reino de los fines es caracterizado como una comunidad ética constituida de racionales, libres y, por consiguiente, moralmente responsables, un mundo inteligible al que pertenecen los hombres en virtud de su condición racional. Todos los seres humanos integran este reino en la medida en que poseen la capacidad de auto-legislarse en sentido práctico (esto es, en sentido moral).

44 Cf. Ibidem, Ak. IV, 436.

45 Ibidem, Ak. IV, 436.

46 Cf. Ibidem, Ak. IV,435.

47 Cf. Ibidem, Ak. IV, 434.

48 Ibidem, Ak. IV, 435.

49 "Fin es un objeto del libre arbitrio, cuya representación determina al libre arbitrio a una acción (por las que se produce aquel objeto). Toda acción tiene, por tanto, un fin [...] puesto que hay acciones libres, tiene que haber también fines a los que se dirijan como objeto. Pero entre estos fines tiene que haber algunos que a la vez sean deberes [...]. Porque si no hubiera fines semejantes, y puesto que ninguna acción humana puede carecer de fin, todos los fines valdrían para la razón práctica sólo como medios para otros fines y sería imposible un imperativo categórico; lo cual anularía toda la doctrina de las costumbres" (I. Kant, La metafisica de las costumbres, Ak. VI, 386). Mendonça observa que Kant hace depender de estos fines que constituyen, a la vez, deberes, la posibilidad misma de un imperativo categórico y, con ello, de una filosofía moral pura (cf. W. Mendonça, “Die Person als Zweck an sich", en Kant-Studien 84, 1993, pp. 167-184, aquí p. 178). Tanto la concepción del hombre como fin en sí como la idea de que toda acción humana persigue un fin, revelan la dimensión teleológica presente en la doctrina ética kantiana (cf. W. Mendonça, op. cit., pp. 178-179). Esta dimensión se hace evidente, asimismo, en la caracterización kantiana de la ética como el sistema de los fines de la razón pura práctica (cf. Ibidem, Ak. VI, 381).

50 Cf. Ibidem, Ak. VI, 386. La felicidad propia nunca puede ser considerada como un deber, puesto que nos hallamos naturalmente inclinados a buscarla, y el concepto de deber se halla, en este marco, esencialmente vinculado con el concepto de coerción.

51 Cf. Ibidem, Ak. VI, 444ss.

52 Cf. Ibidem, Ak. VI, 387. 
En cuanto al deber de procurar la felicidad de otros, la benevolencia, la gratitud, la solidaridad, son deberes que nacen del respeto que se les debe en tanto es reconocida su dignidad humana ${ }^{53}$. El respeto por la dignidad de la persona es, por consiguiente, el fundamento último de todos nuestros deberes:

Todo hombre tiene un legítimo derecho al respeto de sus semejantes y también él está obligado a lo mismo, recíprocamente, con respecto a cada uno de ellos. La humanidad misma es una dignidad [Die Menschheit selbst ist eine Würde] porque el hombre no puede ser utilizado únicamente como medio por ningún hombre (ni por otros, ni siquiera por sí mismo), sino siempre a la vez como fin, y en esto consiste precisamente su dignidad (la personalidad), en virtud de la cual se eleva sobre todos los demás seres del mundo que no son hombres y que sí pueden utilizarse; por consiguiente, se eleva sobre todas las cosas. Así pues, de igual modo que él no puede autoenajenarse por ningún precio (lo cual se opondría al deber de la autoestima), tampoco puede obrar en contra de la autoestima de los demás como hombres, que es igualmente necesaria; es decir, que está obligado a reconocer prácticamente la dignidad de la humanidad en todos los demás hombres, con lo cual reside en él un deber que se refiere al respeto que se ha de profesar necesariamente a cualquier otro hombre ${ }^{54}$.

El respeto mutuo que los hombres deben profesarse se funda en la dignidad inherente al género humano; y dado que a partir de la idea de la humanidad como fin en si emanan deberes éticos específicos ${ }^{55}$, puede sostenerse que la fórmula de la humanidad supone la introducción de un componente material en el marco de una doctrina ética de carácter eminentemente formal. Pese a las indicaciones de Kant respecto del carácter equivalente de las diversas formulaciones del imperativo categórico, al invocar la noción de la humanidad como fin en sí, la segunda fórmula introduce un aspecto que no se halla implícito en la primera fórmula, de carácter abstracto y puramente formal ${ }^{56}$.

\footnotetext{
Cf. Ibidem, Ak. VI, 323, 462.

Ibidem, Ak. VI, 462.
}

55 "La virtud, entendida como conformidad de la voluntad con todo deber [...] es sólo, como todo lo formal una y la misma. Pero atendiendo al fin [...] es decir, a aquello (material) que debemos proponernos como fin, puede haber más virtudes, y la obligación con respecto a la máxima de perseguirlo se llama deber de virtud; por tanto, hay muchos deberes de virtud" (Ibidem, Ak. VI, 395).

56 Respecto de este punto, coincidimos con Paton en que esta segunda formulación no puede entenderse como una mera derivación - ni como un equivalente - de la primera fórmula, por cuanto aporta un contenido que no se halla presente en la fórmula de la ley universal, a saber: la concepción del hombre como fin en sí. Paton señala que tal concepción no sólo introduce un componente material en la ética kantiana, sino que incluso puede ser considerada como fundamento del imperativo categórico: "Granted that a categorical imperative enjoins the treatment of rational agents as ends-in-themselves, in what sense can we say that rational agents are also the grounds of a categorical imperative? There seem to be three senses in which this can be said. Firstly, it because rational agents exist that a categorical imperative must enjoin respect for their rational wills. Secondly, it is because rational agents exist with wills which can be thwarted or furthered in different ways is recognise particular categorical imperatives we ought not wills by fraud or violence, and we ought to further their happiness. Thirdly, it is only because rational agents exist that there can be such a thing as a categorical imperative at all. Because agents are rational, their will necessarily manifests itself in universal laws. Because they are imperfectly rational, these universal laws must appear as categorical imperatives. The categorical imperative has its ground in the will of rational agents who are not completely rational" (H. J. Paton, The Categorical Imperative, op. cit., p. 170). Estas observaciones sugieren que la primera formulación del imperativo categórico no necesariamente 
En cuanto a los deberes específicos que se derivan a partir de la fórmula del hombre como fin en sí mismo, Kant sostiene que el desarrollo y perfeccionamiento de aquello que es propiamente humano debe ser asumido como un fin de nuestras acciones:

El principio supremo de la doctrina de la virtud es el siguiente: obra según una máxima de fines tales que proponérselos pueda ser para cada uno una ley universal. Según este principio, el hombre es fin tanto para sí mismo como para los demás, y no basta con que no esté autorizado a usarse a sí mismo como medio ni a usar a los demás [...], sino que es en sí mismo un deber del hombre proponerse como fin al hombre en general ${ }^{57}$.

Todo hombre está moralmente obligado a considerar a otros hombres, no sólo como fines en sí, sino, además, como un fin propio, y esto significa que ha de contribuir activamente a que otros puedan realizar sus propios fines $^{58}$ : "cuando se trata de la felicidad, de aquella que debe ser para mí un deber fomentar como un fin mío, entonces tienen que ser la felicidad de otros hombres, cuyo fin (permitido) hago yo con ello también mío" 59 . Proponerse la felicidad ajena como un deber de todo hombre para con los demás, implica que cada uno ha de promover el bienestar físico y la integridad moral de otros hombres, para lo cual las relaciones intersubjetivas deben desarrollarse, literalmente, como relaciones interpersonales ${ }^{60}$.

El deber moral de considerar al otro no sólo como un medio sino siempre, a la vez, como un fin en sí mismo, entendido como el deber de contribuir activamente a que pueda alcanzar sus propios fines, presupone el reconocimiento del otro como un ser dotado de una dignidad especial. Es a partir del reconocimiento de esa dignidad, y de los derechos originarios que se siguen de ella, que surgen nuestras obligaciones para con el otro, tanto morales como jurídicas ${ }^{61}$. Asumir un deber para con otro pre-

ha de ser pensada como el principio fundamental de la doctrina ética kantiana, ya que la posibilidad misma de un imperativo parece depender de la concepción del hombre como un ser racional. Más allá de la posición que se asuma respecto de esta interpretación, consideramos acertado reconocer, en la segunda formulación del imperativo, la presencia de un aspecto material en el desarrollo la doctrina ética kantiana, pese al carácter formal que dicha doctrina presenta en sus principios más generales.

57 Cf. I. Kant, La metafisica de las costumbres, Ak. VI, 395.

58 Cf. I. Kant, Fundamentación de la metafísica de las costumbres, Ak. IV, 430.

59 I. Kant, La metafisica de las costumbres, Ak. VI, 388.

60 Como señala Mendonça, el concepto de persona denota una dignidad y valor intrínsecos del ser humano (cf. W. Mendonça, "Die Person als Zweck an sich", op. cit., p. 184). La moralidad es el ámbito en el que puede darse, propiamente, la existencia de personas: el hombre es persona en la medida en que se propone fines, algunos de los cuales son representados por la razón práctica como deberes incondicionados. Para un análisis pormenorizado de la relación entre la concepción del hombre como fin en sí mismo y la teoría kantiana del derecho cosmopolita, remitimos a nuestro trabajo: I. Beade, "Acerca del concepto de dignidad humana en la filosofía kantiana: del hombre como fin en sí mismo al hombre como ciudadano del mundo", en Revista de Estudios Kantianos, vol. 1, 2016, pp. 27-42.

61 Como hemos sugerido en la sección anterior, son las obligaciones morales las que dan lugar a las obligaciones jurídicas. En efecto, en el marco de la teoría kantiana del contrato, la institución del orden civil no es resultado de una acción contingente, sino de un deber práctico (supra, nota 7). A diferencia de otros autores contractualistas, Kant concibe el paso del estado de naturaleza al estado civil como un tránsito necesario, resultado de un mandato práctico incondicionado, y aquí reside uno de los rasgos distintivos del contractualismo kantiano (cf. W. Kersting, op.cit., p.145; A. Ripstein, op.cit., pp. 352ss.). Sin embargo, no hay consenso entre los intérpretes respecto del tipo de exigencia práctica implicada en dicho mandato (cf. R. Pippin, op. cit., pp. 63-85); si bien 
supone reconocer un derecho que le es inherente, ya se trate de un derecho natural o de un derecho positivo. Del mismo modo, asumir un deber para consigo mismo supone reconocer, en la propia persona, la dignidad (y el derecho) que puedo arrogarme en tanto persona.

\section{Algunas consideraciones finales}

El análisis previo ha tenido como objeto aportar algunos elementos relevantes para la elucidación de la relación entre las nociones de deber y derecho en el marco de la filosofía práctica kantiana. A través de dicho análisis, hemos intentado señalar que, en la idea de dignidad humana, así como en el principio del derecho natural, se funda toda obligación en general, tanto ética como jurídica. El análisis del concepto kantiano de derecho ha permitido constatar que no puede hablarse de derecho en sentido estricto sin que otros reconozcan la obligación de respetar ese derecho, de tal modo que el derecho de uno supone, en todo caso, una obligación para otros (esos otros exigirán, a su vez, que les sea reconocido el mismo derecho que reconocen al otro, siendo esta reciprocidad, propia del derecho, correlativa a una reciprocidad en la obligación). Por otra parte, al examinar el concepto de dignidad humana invocado en la segunda formulación del imperativo categórico, hemos observado que el valor intrínseco inherente a todo ser humano en virtud de su condición racional, debe ser respetado tanto en la propia persona como en la persona del otro. Esta idea de dignidad es correlativa a la idea de derechos humanos originarios: si el hombre posee dignidad, i.e. valor intrínseco, es en su carácter de sujeto racional y, más precisamente, en su carácter de ser dotado de libre arbitrio; y es esta misma condición de sujeto racional y libre aquello que lo califica como sujeto de derecho. Podemos concluir, a partir de lo dicho, que tanto los derechos como los deberes son resultado del status racional del hombre y, más precisamente, de su racionalidad práctica.

Kant ha ofrecido una formulación sucinta - que ha devenido clásica- de las preguntas fundamentales por las que se interroga el pensar filosófico: "¿qué puedo saber? ¿qué debo hacer? ¿qué puedo esperar?"62. En sus Lecciones de Lógica, estas preguntas confluyen en un interrogante que, en cierto modo, las sintetiza y articula, a saber: ¿qué es el hombre? [Was ist der Mensch?] ${ }^{63}$. Si la teoría crítica del conocimiento procura responder a la primera de estas preguntas, mientras que la doctrina ética aborda la segunda, y las reflexiones histórico-filosóficas y jurídico-políticas intentan dar respuesta a la tercera, la respuesta de Kant a la pregunta final no sólo puede ser reconstruida a través de un análisis de sus escritos antropológicos ${ }^{64}$, sino

algunos pasajes sugieren que el contrato es resultado de un mandato moral, en La metafisica de las costumbres Kant caracteriza la exigencia de ingresar en una constitución civil como un deber jurídico (cf. I. Kant, La metafisica de las costumbres, Ak. VI, 237). Algunos intérpretes han señalado, en relación con dicha caracterización, que el estado de naturaleza kantiano no es sólo un estado social, sino que es además un estado jurídico, en el que rige lo que Kant caracteriza como "derecho privado" (cf. F. González Vicén, La filosofía del estado en Kant, Universidad de la Laguna, 1952, pp. 57-58).

62 I. Kant, Crítica de la razón pura [Kritik der reinen Vernunft, 1781/1787], traducción de M. Caimi, Buenos Aires, Colihue, 2007, Ak. III, A 805/B 833.

63 I. Kant, Lógica [Logik. Ein Handbuch zu Vorlesungen, 1800], traducción de M. J. Vázquez Lobeiras, Madrid, Akal, 2000, Ak. IX, 25.

64 Cf. I. Kant, Antropología desde un punto de vista pragmático [Anthropologie in pragmatischer Hinsicht, 1798], 
que ha de ser reconocida como una inquietud transversal a la filosofía crítica, una pregunta implícita que recorre tanto sus obras gnoseológicas como las morales, así como sus textos jurídicos, políticos, pedagógicos, estéticos, histórico-filosóficos e incluso sus escritos sobre filosofía de la religión. Las breves reflexiones vertidas a lo largo de estas páginas permiten apuntar algunos aspectos que deben ser tenidos en cuenta al momento de abordar esta pregunta antropológica -o, quizás, ontológico-práctica- referida al ser del hombre. En el marco de la filosofía crítica, el hombre es concebido como un ser racional, un ser dotado de libre arbitrio, vinculado a un mandato moral cuyo origen reside en su propia razón. En virtud de su condición racional, el hombre es pensado como un sujeto de derecho, como un ser dotado de valor intrínseco, de una dignidad que ha de ser respetada y honrada, más allá de toda circunstancia. El hombre es persona, i.e. posee la capacidad de auto-legislarse, y la autonomía que le es propia asume, en este marco, tanto una dimensión moral como una dimensión jurídico-política. Hemos señalado, por otra parte, que en virtud de un mandato moral -esto es, de un principio racional puro, de carácter incondicionadoel hombre es inducido a la creación de instituciones civiles, en cuyo marco pueda ser legalmente garantizado el ejercicio de sus derechos básicos. Sólo en el estado civil - entendido como un estado de derecho público- pueden los seres humanos garantizar la reciprocidad del derecho, entendida ésta como la única condición bajo la cual los hombres pueden existir, en sentido propio, como personas, esto es, como fines en sí mismos. Asumir la idea del hombre como fin en sí, esto es, la noción dignidad humana, como principio limitativo de mis acciones, es actuar conforme a la premisa que establece la existencia de derechos humanos originarios e inalienables. Este es el criterio último e inapelable que permite establecer, en este contexto doctrinal, el valor de las acciones y aquello que permite delinear los contornos del concepto de justicia ${ }^{65}$. En este sentido, las nociones de dignidad humana, de derechos naturales y-cabría añadir aquí- el concepto de justicia, constituyen los pilares fundamentales sobre los que se alza el edificio completo de la filosofía práctica kantiana, nociones que se implican mutuamente, y que -según hemos sugerido a lo largo de estas páginas- definen lo más propio y singular de la condición humana.

traducción de M. Caimi, Buenos Aires, Losada, 2009. Cf. asimismo: I. Kant, Antropología práctica (según el manuscrito inédito de C.C. Mrongovius, fechado en 1785), traducción de R.Rodríguez Aramayo, Madrid, Tecnos, 1990.

65 Si bien nos hemos podido considerar aquí el concepto de justicia y su importancia en el desarrollo de la metafísica jurídica kantiana, podemos señalar, al menos, que se trata de un concepto íntimamente relacionado con el concepto de derecho y, por extensión, también con el de dignidad humana. En el marco de esta conexión han de ser interpretada la célebre observación kantiana: "Porque si perece la justicia, carece ya de valor que vivan hombres sobre la tierra" (I. Kant, La metafisica de las costumbres, Ak. VI, 332). 